\title{
A SERIAL STUDY OF THE EFFECTS OF FINGER-SUCKING
}

ALLAN T. RUTTLE, D.D.S., M.S., WILLIAM QUIGLEY, D.D.S., M.S., JOHN T. CROUCII, D.D.S., M.S., AND GEORGE E. EWAN, D.D.S., M.S.*

University of Michigan, Ann Arbor, Mich.

$\mathrm{O}$ RTHODONTISTS have long been interested in the distorting effects of finger habits upon the denture. With little detailed study and with little collected evidence, clinicians have developed several, often contradictory, viewpoints about the probable and actual effects of these finger habits. Since finger habits are widely practiced by young children, for short or long periods of time, it is important to ascertain the impact of these habits upon the denture and to establish their contribution to the etiology of malocclusion. The serial orthodontic models in the laboratory of child development at the University of Michigan are sufficiently extensive to begin a systematic attack upon this problem.

\section{DATA}

Since 1931, systematic seriatim records on child development have been taken at the University of Michigan, the university conducting a thorough growth study of all its students. Included are psychological, educational, growth, medical, and dental records. The dental history consists of annual orthodontic models and a biannual oral examination. All observations for this study were taken from the orthodontic casts. Serial records of various lengths for some 1,700 children have been compiled to date.

Thirty-six children, who have long records, present definite and persistent oral habits. The detailed distribution of these data is recorded in Table $I$. Thumb-sucking predominates, occurring in twenty-three instances, with fingersucking limited to three children, and such compound oral habits as thumbsucking, finger-sucking, and nail-biting accounting for the remaining ten individuals. All habits, except one, started during the first year of life. The age at which the first cast was taken appears in Column 3 (Table I), and the age at which the last habit record was taken appears in Column 4 . The age at the last model, the length of the record, the number of casts for each child, and the length of time that the habit was operating are shown in the remaining columns of the table. Seven cases received orthodontic treatment at various ages. It was necessary to eliminate those casts immediately following the initiation of treatment. These are recorded as treated.

The independent theses submitted in partial fulfillment of requirements for the degree of Master of Science in Orthodontics at the University of Michigan are rewritten fointly by the four authors for publication.

Received for publication, Dec. 16, 1952; revised by authors, Aug. 1, 1953.

* Present address: Sheridan, Wyo. 
TABLE I

Distributron of Type and Duration of Habit in Months

\begin{tabular}{|c|c|c|c|c|c|c|c|}
\hline $\begin{array}{c}\text { CASE } \\
\text { NUMBER }\end{array}$ & $\begin{array}{l}\text { TYPE OF } \\
\text { HABIT }^{*}\end{array}$ & $\begin{array}{c}\text { AGE AT } \\
\text { FIRST } \\
\text { CAST }\end{array}$ & $\begin{array}{l}\text { AGE WHEN LAST } \\
\text { OBSERVED } !\end{array}$ & $\begin{array}{c}\text { AGE AT } \\
\text { LAST } \\
\text { CAST }\end{array}$ & $\begin{array}{c}\text { LENGTH } \\
\text { OF } \\
\text { RECORD }\end{array}$ & $\begin{array}{c}\text { NUMBER } \\
\text { OF } \\
\text { CASTS }\end{array}$ & $\begin{array}{c}\text { LENGTH } \\
\text { OF HABIT } \\
\text { RECORD }\end{array}$ \\
\hline 1 & TS & 66 & 96 Stopped & 198 & 132 & 11 & 30 \\
\hline 2 & TS & 79 & 121 Stopped & 191 & 112 & 9 & 42 \\
\hline 3 & FS & 56 & 107 Stopped & 205 & 149 & 11 & 51 \\
\hline 4 & TS & 40 & 97 Treated & 97 & 57 & 5 & 57 \\
\hline 5 & TS & 80 & 113 Stopped & 213 & 133 & 9 & 33 \\
\hline 6 & TS and FS & 49 & 122 Stopped & 186 & 137 & 11 & 73 \\
\hline 7 & ES & 76 & 123 Stopped & 220 & 144 & 12 & 47 \\
\hline 8 & TS & 42 & 97 Treated & 97 & 55 & 6 & 55 \\
\hline 9 & FS and TT & 43 & 84 Treated & 67 & 24 & 3 & 41 \\
\hline 10 & $\mathrm{TS}$ & 39 & 84 Stopped & 120 & 81 & 7 & 45 \\
\hline 11 & TS & 48 & 48 Continuing & 48 & & 1 & \\
\hline 12 & $\mathrm{TS}$ & 43 & 90 Continuing & 90 & 47 & 4 & 47 \\
\hline 13 & $\mathrm{TS}$ and $\mathrm{TT}$ & 73 & 98 Continuing & 109 & 36 & 4 & 25 \\
\hline 14 & TS & 60 & 84 Continuing & 84 & 24 & 3 & 24 \\
\hline 15 & TS & 44 & 72 Continuing & 72 & 28 & 4 & 28 \\
\hline 16 & $\underset{\text { TT }}{\mathrm{TS}}$ & 64 & 135 Stopped & 182 & 118 & 11 & 71 \\
\hline 17 & TS and FS & 96 & 120 Treated & 120 & 24 & 3 & 24 \\
\hline 18 & TS and NB & 60 & 100 Stopped & 192 & 132 & 6 & 40 \\
\hline 19 & $\mathrm{FS}$ & 34 & 84 Stopped & 121 & 87 & 8 & 50 \\
\hline 20 & TS and FS & 69 & 138 Treated & 138 & 69 & 7 & 69 \\
\hline 21 & TS & 60 & 142 Stopped & 153 & 93 & 8 & 82 \\
\hline 22 & TS & 79 & 198 Continuing & 198 & 119 & 11 & 119 \\
\hline 23 & TS & 77 & 122 Stopped & 198 & 121 & 9 & 45 \\
\hline 24 & TS & 74 & 165 Treated & 165 & 91 & 5 & 91 \\
\hline 25 & TS and FS & 60 & 84 Stopped & 192 & 132 & 9 & 24 \\
\hline 26 & $\mathrm{TS}$ & 52 & 102 Stopped & 196 & 144 & 13 & 50 \\
\hline 27 & $\mathrm{TS}$ and $\mathrm{TT}$ & 84 & 108 Continuing & 108 & 24 & 3 & 24 \\
\hline 28 & $\mathrm{TS}$ & 60 & 108 Continuing & 117 & 57 & 4 & 48 \\
\hline 29 & TS & 108 & 108 Continuing & 108 & & 1 & \\
\hline 30 & TS & 41 & 54 Continuing & 54 & 13 & 2 & 13 \\
\hline 31 & $\mathrm{TS}$ & 91 & 138 Continuing & 138 & 47 & 4 & 47 \\
\hline 32 & $\mathrm{TS}$ & 42 & 90 Continuing & 99 & 57 & 5 & 48 \\
\hline 33 & $\mathrm{TS}$ & 60 & 84 Continuing & 94 & 34 & 4 & 24 \\
\hline 34 & $\mathrm{TS}$ and $\mathrm{TT}$ & 54 & 114 Continuing & 116 & 62 & 6 & 60 \\
\hline 35 & TS & 60 & 106 Continuing & 106 & 46 & 5 & 46 \\
\hline 36 & TS & 54 & 81 Continuing & 81 & 27 & 3 & 27 \\
\hline
\end{tabular}

*TS, Thumb-sucking; TT, tongue-thrusting; FS, finger-sucking; NB, nail-biting.

+ All habits commenced during the first year of life, with the exception of Case 24 , which started at 30 months of age.

A comparable set of observations were secured upon forty-two nonhabit cases. This evidence is presented in Table II.

\section{OBSERVATIONS}

Arch Form.-Arch form was classified as tapering, trapezoid, and ovoid since other arch types were not observed. A tapering arch (Fig. 1) converges from the molars to the first incisors to such an extent that lines passing through the central grooves of the molars and premolars intersect within 1 inch anterior to the first incisors. A trapezoidal arch (Fig. 2) shows the same type of convergence toward the midline as the tapering arch, but to a lesser 
TABLE II

Distribution of Nonhabit Cases and Duration in Monthis

\begin{tabular}{|c|c|c|c|c|}
\hline $\begin{array}{c}\text { CASE } \\
\text { NUMBER }\end{array}$ & $\begin{array}{c}\text { AGE AT } \\
\text { FIRST CAST }\end{array}$ & $\begin{array}{c}\text { AGE } \Lambda \mathrm{T} \\
\text { LAST CAST }\end{array}$ & $\begin{array}{c}\text { I } A \text { ENGTH OF } \\
\text { RECORD }\end{array}$ & $\begin{array}{c}\text { NUMBER OF } \\
\text { CASTS }\end{array}$ \\
\hline$\frac{1}{1}$ & 59 & 112 & 53 & 6 \\
\hline 2 & 74 & 169 & 95 & 9 \\
\hline 3 & 76 & 137 & 61 & 6 \\
\hline 4 & 67 & 134 & 67 & 7 \\
\hline 5 & 85 & 198 & 113 & 9 \\
\hline 6 & 100 & 196 & 96 & 9 \\
\hline 7 & 63 & 194 & 131 & 10 \\
\hline 8 & 71 & 203 & 132 & 12 \\
\hline 9 & 58 & 153 & 95 & 8 \\
\hline 10 & 122 & 223 & 101 & 9 \\
\hline 11 & 37 & 191 & 154 & 12 \\
\hline 12 & 42 & 131 & 89 & 6 \\
\hline 13 & 72 & 206 & 134 & 8 \\
\hline 14 & 53 & 196 & 143 & 12 \\
\hline 15 & 75 & 159 & 84 & 8 \\
\hline 16 & 73 & 215 & 142 & 12 \\
\hline 17 & 64 & 194 & 130 & 11 \\
\hline 18 & 38 & 169 & 131 & 12 \\
\hline 19 & 72 & 205 & 133 & 12 \\
\hline 20 & 65 & 208 & 143 & 12 \\
\hline 21 & 87 & 185 & 98 & 9 \\
\hline 22 & 46 & 156 & 110 & 9 \\
\hline 23 & 96 & 200 & 104 & 10 \\
\hline 24 & 90 & .132 & 42 & 4 \\
\hline 25 & 64 & 146 & 82 & 8 \\
\hline 26 & 64 & 156 & 92 & 10 \\
\hline 27 & 84 & 102 & 18 & 2 \\
\hline 28 & 55 & 208 & 153 & 14 \\
\hline 29 & 46 & 213 & 167 & 13 \\
\hline 30 & 49 & 215 & 166 & 14 \\
\hline 31 & 69 & 122 & 53 & 5 \\
\hline 32 & 41 & 172 & 131 & 10 \\
\hline 33 & 77 & 147 & 70 & 7 \\
\hline 34 & 74 & 209 & 135 & 9 \\
\hline 35 & 44 & 185 & 141 & 12 \\
\hline 36 & 62 & 166 & 104 & 9 \\
\hline 37 & 54 & 126 & 72 & 7 \\
\hline 38 & 39 & 121 & 82 & 8 \\
\hline 39 & 43 & 186 & 143 & 10 \\
\hline 40 & 43 & 209 & 166 & 15 \\
\hline 41 & 42 & 183 & 141 & 13 \\
\hline 42 & 47 & 184 & $13 \overline{7}$ & 12 \\
\hline
\end{tabular}

degree. The anterior teeth are somewhat squared to abruptly rounded from canine tip to canine tip. The canine teeth act as corners of the arch. Ovoid arches (Fig. 3) curve continuously from the molars of one side to the molars of the opposite side in such a way that two such arches placed back to back describe an oval.

Both maxillary and mandibular arches were observed and tabulated according to the requirements just mentioned. The depth of bite, true overjet, apparent overjet, anterior spacing, anterior crowding, and arch widths for maxillary and mandibular deciduous and permanent canines, deciduous molars and premolars, and first permanent molars were measured by the use of the Boley or Helios gauge, the choice being that which best fitted the observation.

Depth of Bite.-The depth of bite was determined by measuring the average overlapping of the labial surfaces of the mandibular first incisors by the 
lingual surfaces of the maxillary first incisors. This measurement was made vertically on the mandibular first incisors from the incisal edge to a point on the labial surface in line with the maxillary incisal edges and parallel to the occlusal plane. The degree of open-bite is the average distance from the incisal edges of the maxillary first incisors to the incisal edges of the mandibular first incisors, measured vertically and perpendicular to the occlusal plane. These measurements on depth of bite and open-bite were not taken if the maxillary and mandibular first incisors were less than two-thirds erupted, and in cases where edentulous spaces existed.

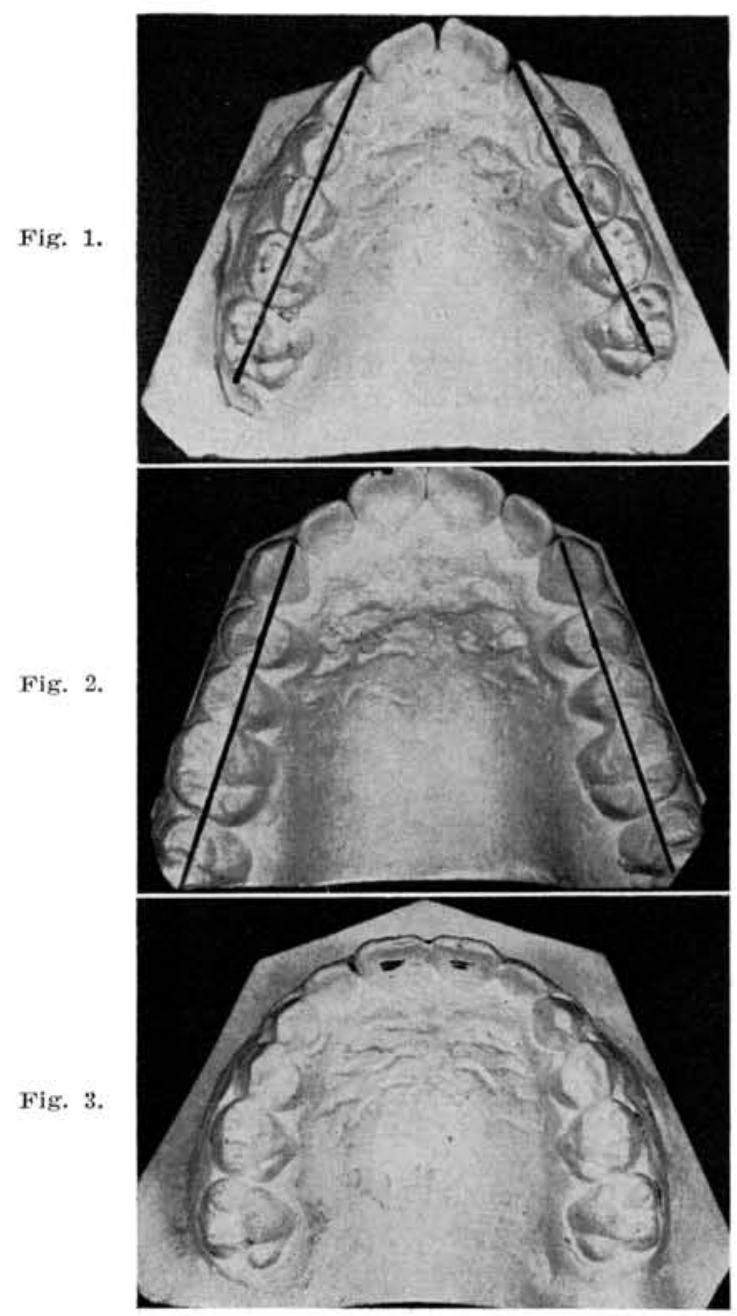

True Overjet.-The grade of overjet is listed as zero when the incisal edges of the mandibular first incisors contact the lingual surfaces of the maxillary first incisors just incisal to the cervical prominences, or cingula. Deviations from this state in an anterior or posterior direction and parallel to the occlusal plane are recorded in millimeters. 
Apparent Overjet.-Apparent overjet is the distance from the labial surface of the mandibular first incisors to the labial-incisal angle of the maxillary first incisors measured parallel to the occlusal plane.

Anterior Spacing.-Anterior spacing was measured by placing the arms of the Boley gauge perpendicular to the lateral edges of the space. The total amount of space, secured by adding the individual measurements, was recorded.

Canine Width. - The canine width measured on the maxillary and mandibular deciduous and permanent canines is the greatest dimension between the labial surfaces of the respective canines.

First Molar Arch Width.- The first molar arch width is the maximum diameter between the buccal surfaces at the gingival line. It was recorded for permanent and deciduous teeth.

First Premolar Arch Width.-The first and second premolar arch width was obtained by measuring the distance between the most marked convexities of the buccal tooth surfaces. Maxillary and mandibular measurements were recorded.

Deciduous Second Molar Arch Width.-The maxillary and mandibular deciduous second molar arch width is the distance between points where extensions of the buccal grooves intersect with the gingival line.

Classification of Molar Occlusion.-The Angle classification of occlusion was used for the first permanent molars. An equivalent system was used for the second decidnous molars, which were used for this classification as long as they were present. Variations from Class I (Angle) are indicated in terms of quarters of a cusp.

Classification of Canine Occlusion.-Canine occlusion is described as Class I when the tip of the upper canine interdigitates in the embrasure between the lower canine and first premolar. It is called Class II if the upper canine is mesial to this embrasure, and Class III if it is distal to it. Variation toward Class II or Class III was recorded in quarters of a cusp.

\section{RFSULTS}

Analysis.-The Chi-square Goodness of Fit* has been used to reduce these data in a way to permit comparison between the habit and the nonhabit groups (Table III). The chance frequency $\mathrm{E}$ represents the type of distribution one would obtain if no associative factors were operative. The actual frequency is given as $\mathrm{A}$. The Chi-square value $\left(\mathrm{X}^{2}\right)$ is a statistical computation stating whether or not the differences shown are dependent upon real associative factors or whether they have to be ascribed to chance. The sum of the Chi-square values indicates the statistical significance and $P$ is a statement of the chances out of 100 of this Chi-square sum being significant.

*For detailed development and discussion of the Chi-square technic see Peters and Van Voorhis, Statistical Procedures and Their Mathematical Bases, ed. 1, New York, 1940, McGrawHill Book Company, Inc., pp. 404-24. 
Maxillary Arch Form.-The effect of prolonged finger-sucking upon the maxillary arch is demonstrated in Table III. The habit operates to alter the arch form in such a way as to give a higher frequency of tapered arches and a lower frequency of ovoid arches and no significant change in the frequency of trapezoid arches. This distribution of frequency is assignable to a general tapering of arch form as the effect of the habit, operating to move ovoid into trapezoid and tapering arch forms, and trapezoid to tapering. The differences shown in the table are statistically of high significance, with the probability of ascribing this change to chance being less than 1 in $100(P=0.01)$.

TABLE IIT

Maxillary Arch Form

\begin{tabular}{|c|c|c|c|c|}
\hline & TAPERING & TRAPEZOID & OVOID & TOTAL \\
\hline Habit & $\begin{array}{l}\mathrm{E}-3.69 \\
\mathrm{~A}-6 \\
\mathrm{X} 2 \quad 1.44\end{array}$ & $\begin{array}{l}\mathrm{E}-28.6 \mathrm{I} \\
\mathrm{A}-30 \\
\mathrm{X}^{2} \quad 0.07\end{array}$ & $\begin{array}{l}\mathrm{E}-3.69 \\
\mathrm{~A}-0 \\
\mathrm{X}^{2} \quad 3.69\end{array}$ & 36 \\
\hline Nonhabit & $\begin{array}{l}\mathrm{E}-4.31 \\
\mathrm{~A}-2 \\
\mathrm{X}^{2} \quad 1.24\end{array}$ & $\begin{array}{l}\mathrm{E}-33.38 \\
\mathrm{~A}-32 \\
\mathrm{X}^{2} \quad 0.06\end{array}$ & $\begin{array}{l}\mathrm{E}-4.31 \\
\mathrm{~A}-8 \\
\mathrm{X}^{2} \quad 3.16\end{array}$ & 42 \\
\hline Total & 8 & 62 & 8 & 78 \\
\hline Sum of $\mathrm{X}^{2}=$ & 9.66 & $\mathrm{P}=0.01$ & & \\
\hline
\end{tabular}

Mandibular Arch Form.-The mandibular arch in the habit series presents a more pronounced angulation at the canine and a flattening of the incisors. There is little difference between the labial inclination of the mandibular anteriors in the habit and nonhabit groups. The habit acts to retrude the anterior part of the denture as a whole without changing the inclination of the teeth. This change reduces ovoid and tapering arches and increases trapezoidal arches in the habit group. The change is significant $(P=0.02)$.

Anterior Depth of Bite.-The evidence makes it clear that finger habits operate to produce open-bite malocelusions $(\mathrm{P}=0.01)$. The detailed distribution indicates that ten of the thirty-six habit cases are in definite open-bite relationship, whereas in the nonhabit series no open-bite occlusion is shown. The further suggestion, then, is that finger habits presumably represent the major etiological source of this type of malocclusion affecting approximately one-third of all dentures with this habit.

True and Apparent Overjet.--The differences between the habit and nonhabit groups warrant the conclusion that thumb and finger habits produce a major amount of modification in the anterior part of the maxillary arch. The difference in incidence is apparent, with the habit series presenting 45 per cent moderate to extreme true overjet and the nonhabit series showing 9 per cent with true overjet in these categories. The difference between these two percentages shows the habit to produce distortion at the 36 per cent level.

Apparent overjet $(P=0.01)$, like true overjet $(P=0.01)$, is without question another major effect of finger-sucking. Here we find 40 per cent of the habit group and only 5 per cent of the nonhabit group. The marked 
difference between the groups at the extreme reveals more clearly the impact of the distortion. Thus, it is realized that true overjet and apparent overjet will occur together many times, although there are some cases in which apparent overjet, due mainly to a labial tipping of the maxillary anteriors, occurs without the development of excessive true overjet. It is questionable, however, that apparent overjet has a higher elinical significance than does true overjet.

Distribution of True and Apparent Overjet.-While the directional distribution of true overjet changes are relatively balanced, apparent overjet shows a definite tendency to inerease throughout both the habit (58.8 per cent) and the nonhabit series (52.4 per cent).

The apparent overjet increases independently of any increase in true overjet in 23.5 per cent of the habit eases and in 23.8 per cent of the nonhabit group; conversely, the true overjet increases independently of directional changes in apparent overjet in only one (2.5 per cent) of the habit eases and in no cases of the nonhabit group.

This discrepancy, by careful visual observations, appears to be mainly the result of an increase in labial inclination of the maxillary incisors, with or without a slight lingual movement of the mandibular incisors.

\section{Shift from Anterior Deciduous Spacing to Anterior.-}

Permanent crowding: The percentage distribution of transgression from anterior spacing in the deciduous dentition to anterior crowding in the permanent dentition of twenty-seven habit and thirty-nine nonhabit cases is presented. Four cases (14.8 per cent) in the habit series shifted from maxillary anterior spacing of the deciduous teeth to crowding of the maxillary permanent anteriors. In contrast, seventeen cases ( 43.6 per cent) of the nonhabit series revealed a transition from spacing to crowding of the maxillary anteriors.

In the mandibular arch, there are no particularly significant differences between the habit and nonhabit series with respect to a shift from deciduous anterior spacing to anterior crowding of the permanent teeth. It is evident, then, that oral habits act in such a manner as to retard any inherent tendency for a transition from maxillary deciduous anterior spacing to crowding of the permanent anterior teeth. Habit has no similar effect upon the mandibular anteriors.

Distribution of Progressive Changes in Anterior Crowding.-Three cases ( 8.8 per cent) of the habit series and fourteen ( 35.0 per cent) of the nonhabit series show a progressive increase in maxillary anterior crowding. This indicates a greater tendency in the nonhabit cases toward increased erowding in this area. The differences in anterior erowding of the mandibular dentition between the habit and nonhabit groupings are not particularly significant, since ten (29.4 per cent) of the habit series show an increase as compared with fourteen (42.5 per cent) of the nonhabit group showing an increase. That the habit cases show less of a tendency toward maxillary crowding is no doubt 
lue to a distortion of the anterior part of the arch which is often elongated, (see True and Apparent Overjet) with the result that erowding is alleviated and spacing often may develop.

Distribution of Anterior Spacing and Crowding in the Permanent Dentition.-The permanent dentition of the habit group shows a greater tendency toward maxillary anterior spacing than does the nonhabit group. The percentage distribution of these conditions shows eight ( 47 per cent) of the habit and eleven ( 35.5 per cent) of the nonhabit series with spacing in this region. Crowding is present in five (29.4 per cent) of the habit cases and in thirteen (41.9 per cent) of the nonhabit cases.

No significant differences, either clinical or statistical, between the two groups are observed in either mandibular spacing or crowding in the permanent dentition.

It is evident, then, that oral habits are conducive to maxillary anterior spacing in the permanent dentition.

Maxillary Arch Width (Canine).-There is no evidence that the deciduous canine arch width in the maxilla and the mandible, or the permanent canine mandibular arch width, is altered by thumb-sucking. Likewise, canine occlusion is unaffected. The Chi-square Goodness of Fit analysis does not make the effects of oral habits particularly clear in the maxillary arch width at the permanent canines. A numerical analysis of amount of change, however, is informative. The average decrease of the twelve nonhabit cases showing a decrease is $0.615 \mathrm{~mm}$., and for those showing an increase it is $1.05 \mathrm{~mm}$. The corresponding averages for the habit group are $1.14 \mathrm{~mm}$. and $0.6 \mathrm{~mm}$., respectively. It appears, therefore, that when maxillary canine arch width is affected by an oral habit the distortion is of a rather marked degree.

Molar Arch Width.-There is no evidence showing deformity in the deciduous molar, premolar, or permanent molar areas of the maxilla or mandible. In the mandibular arch, at the permanent first molar and the deciduous first molar levels, the changes merely approach statistical significance. Conversely, maxillary arch width at the second premolar and first permanent molar levels shows a striking similarity between the habit and nonhabit series.

Molar Occlusion (Angle).-The relationship of the upper and lower molars indicates only an approach toward significance. There is a suggestion that these habits produce a shift toward a Class II molar relationship. The degree of this shift, however, is not marked. Certainly, the contribution of this type of habit to the etiology of Class II malocclusion is not nearly as great as is indicated in the literature. This is in strong contrast to depth of bite, arch form, true overjet, and apparent overjet where the amount of change is large and the elinical significance great.

\section{SUMMARY}

The maxillary arch form is modified in thumb and finger suckers by elongation of the anterior segment. This acts to produce spacing, labial inclina- 
tion, and protrusion of the maxillary incisors. There is a definite opening action in the anterior region. True and apparent overjet are increased strongly, although apparent overjet shows a tendency to increase in the nonhabit, as well as the habit, series.

Sucking habits act in opposition to any inherent tendency for a transition from maxillary deciduous anterior spacing to crowding of the permanent anterior teeth. This effect is not evident in the mandibular anteriors.

The frequency of distortion of the maxillary arch width at the permanent canine level is limited. In a few cases, however, where a distortion does occur it progresses to a rather marked degree.

Modification of the mandibular arch width at the deciduous first molar and the permanent first molar merely approaches statistical significance. Clinical utility of this fact, however, is questionable.

Maxillary arch width, with the infrequent exception of the permanent canine area, is unaffected.

Contrary to most publications, the effect of thumb and finger habits on the molar occlusion merely approaches statistical significance, and does not attain clinical utility.

\section{REFERENCES}

1. Angle, E. H.: Malocclusion of the Teeth, ed. 7, Philadelphia, 1907, S. S. White Co., p. 104-113.

2. Barrow, G. V., and White, J. R.: Ocelusal, Configurational and Dimensional Changes of the Maxillary Dental Arches. A Thesis Submitted in Partial Fulfillment of the Requirements for the Degree of Master of Science in Orthodonties at the Horace A. Rackham School of Graduate Studies at the University of Michigan, Ann Arbor, Mich., May, 1942.

3. Brash, J. C.: The Aetiology of Irregularity and Malocclusion of the Teeth, London, 1929, Dental Board of the United Kingdom, p. 212.

4. Case, C. S.: Dental Orthopedia and Correction of Cleft Palate, ed. 2, Chicago, 1921, C. S. Case Co.

5. Dewey, Martin, and Anderson, G. M.: Practical Orthodontics, ed. 6, St. Louis, 1942, The C. V. Mosby Company, p. 141-3.

6. Garrett, H. E.: Statisties in Psychology and Education, ed. 3, New York, 1947, Longmans, Green \& Co., p. 241-53.

7. Haas, Magda: The Different Sucking Habits and Their Influence on the Development of Dentition, D. Record 57: 633-53, 1937.

8. Hellman, Milo: Studies in Etiology of Angle's Class II Malocclusal Manifestations, Am. Soc. Orthodont. Prac. 21: 76-97, 1921.

9. Hemley, Samuel: Fundamentals of Occlusion, Philadelphia, 1944, W. B. Saunders Company, p. 225-8.

10. Howard, C. C.: Inherent Growth and Influence on Malocclusion, J. A. D. A. 19: 64251,1932 .

11. Jackson, V. H.: Orthodontia and Orthopedia of the Face, Philadelphia, 1904, J. B. Lippincott Company, p. 49-51.

12. Johnson, A. L.: Basic Principles of Orthodontia, D. Cosmos 65: 379-89, 503-18, 596-605, 719-32, 845-61, 957-68, 1923.

13. Johnson, Leland R.: Habits and Their Control During Childhood, J. A. D. A. 24: 1409 $21,1937$.

14. Johnson, Leland R.: The Status of Thumbsucking and Fingersueking, J. A. D. A. 26: 1245-54, 1939.

15. Korkhaus, Gustav: Favourable and Unfavourable Tendencies in Jaw Development, D. Record 56: 161-86, 1936.

16. Lewis, S. J.: Thumb-sucking; a Cause of Malocelusion in the Deciduous Teeth, J. $A$. D. A. 17: 1060-72, 1930 .

17. Lewis, S. J.: Undesirable Habits Influencing the Deciduous Dentition, J. A. D. A. 18: $1766 \cdot 78,1931$. 
18. Lischer, B. E.: Orthodontics, Philadelphia, 1912, Lea \& Febiger, pp. $71-74$

19. Lourie, L. S.: Some Abnormal Functions Associated With Malocelusion, J. A. D. A. 15: $797-805,1928$

20. MeCoy, J. D.: Applied Orthodontia, ed. 6, rev., Philadelphia, 1946, Lea \& Febiger, pp. 91-99.

21. Pullen, H. A.: Abnormal Habits in Their Relation to Malocelusion and Facial Deformity, Internat. J. Orthodontia 13: 233-252, 1927.

22. Sillman, J. H.: Malocelusion in the Deciduous Dentition; Serial Study From Birth to Five Years, Am. J. Orthodontics 28: 197-209, 1942.

23. Strang, Robert H.: Textbook of Orthodontia, Philadelphia, 1943, Lea \& Febiger, pp. $138-50$

24. Swinehart, Earl: Structural and Nervous Effects of Thumb-sucking, J. A. D. A. 25: $736-47,1938$.

25. Swinehart, Earl: Relation of Thumb-sueking to Malocclusion, Am. J. Orthodontics 24: 509-21, 1938. 